\title{
Word-Images: Politics and Visual Cultures in China
}

\section{Maurizio Marinelli, University of Technology Sydney}

In China, word-images have always played a crucial role in the construction of a claimed reality in the socio-political arena. According to the Confucian doctrine, a precise relationship exists between the idea of 'correctness' (zheng 正), as expressed in the paradigm of 'rectification of names' (zhengming 正名), and the art of governing the state (zheng 政) (Confucius 1960: 13.3).

Confucian philosophers argued that names and language embodied norms and had a performative function. By simply speaking or writing the words, an action, a title, a ritual, or an object was meant to become a reality. Thus language set the standards for how ruler and subject should act. In Confucius’s words: 'To govern means to rectify names. If you lead the people by being rectified yourself, who will not be rectified?' (Confucius 1960: 12.17). A ruler able to 'rectify names' could set a clear example for his subjects to follow. When the ruler's behaviour was in line with the standards defined by his words, the ruler was thought to literally embody codes of proper social and political behavior. Conversely, when the behaviour of either ruler or ruled was out of line with the idealized standards ascribed to their social position, the prerogatives that normally attended that position no longer held. A king whose rule strayed from the idealized standards was no longer a proper 'king,' and could be legitimately overthrown and replaced. Confucian epistemology propounded a vertically structured social and ethical hierarchy, and the 'rectification of names' played a crucial role in mediating the correlation between written ideal and orthodox social practice. 
John Makeham argues that Confucius considered names as 'social and political catalysts' (1994: 39-47). Names could be used to describe the reality, but they also had, and more significantly so, a prescriptive function. By using the correct names, the ruler had the opportunity to prescribe sociopolitical distinctions, and therefore to promote correct thought and behaviour both as orthodoxy and orthopraxy.

These fundamental tenets on the proper use of language determined the connection between language, knowledge and power, and informed the practices of governance throughout Chinese history even beyond the apparent divide represented by the creation of the 'New China' in October 1949. During Mao Zedong’s era (1949-1976), the Confucian paradigm connecting ‘correct names’ with governmentality was systematically implemented through vertical and horizontal propaganda, and it was strategically combined with the use of socialist realism-style images as instruments of political action (Barmé 1999; Evans \& Donald 1999). Chinese political discourse was characterized by what Michael Schoenhals (1992) defines as 'formalized language.' The 'newspeak' developed and used by party officials was a restricted code. It consisted of 'correct' formulations (tifa 提法), accompanied by 'correct' images, and aimed to teach the 'enlarged masses' (dazhong 大众) how to speak and, ultimately, how to think. Thus, a set of rules and conventions shared by the official speaker and the listeners defined a logocentric model that represented a claimed reality. These rules were so pervasive that they became encoded in patterns, style, syntagmatic bonds and lexical items typical of formalized word-images. Speech and artworks then followed the expressive devices of regulated discursive formations. A whole generation of ‘characters workers' (wenyi gongzuozhe 文艺工作者) employed both characters and visual texts to contribute to the engineering of a totality, which became the only possible claimed reality. Word-images were inculcated from the top-down, and then absorbed, and interiorized since they carried an intrinsic performative power, leading to the creation of the 'one voice chamber’ [or, more literally, 'one language temple’] (yiyantang 一言堂). As Ludwig Wittgenstein poignantly argued, words and sentences have the power to limit 'expression of thoughts,' because the boundaries of language indicate the boundaries of one's world. 'It will therefore only be in language that the limit can be set, and what lies on the other side of the limit will simply be nonsense' (Wittgenstein 1961: 5-6). 
However, in the Chinese epistemological tradition, while Confucian philosophers believed in the human (and ultimately political) possibility to engineer reality, understand it, name it, and therefore control it, Daoists thought that such endeavours were the major source of human frustration, since they created an increasing gap between humans and nature. According to Daoism, man's only concern should be to fit into the great pattern of nature, not man-made society. The Dao De Jing 道德经 (The Classic of the Way and Its Power), attributed to Laozi, and composed between the late sixth and the late fourth centuries BCE, set forth a series of maxims that outline a perspective on reality very different from that of the Confucian canon.

Confucius used the word Dao 道 usually translated in English as 'Road' or 'Way,' to describe his ideal social system, but the Daoists gave it a metaphysical interpretation and defined Dao as the great pattern of nature. The 'Way' became a discourse, and not a constant 'name'; the process of 'naming' would confine people’s imagination and their ability to understand the universe. Naming is like giving a label: after naming one tends to think of something's nature under that label, and this is contrary to the Dao. This is the rationale behind Laozi's affirmation: 'The one who knows (or is centred) does not speak, the one who speaks does not know.' Therefore, for Laozi (老子), Dao was founded on a nameless, formless 'Non-being': ‘it cannot be heard,' ‘cannot be seen,' and 'cannot be spoken.'

The person who can transcend mundane human distinctions and become one with the Dao is 'beyond all harm' and achieves 'tranquility in the midst of strife.' Merging with the Dao, he derives from it his individual $D e$ 德 or mystical 'power.' De later came to have the moralistic meaning of 'virtue.' Another important concept that helps to understand the Daoist concept of the relation between naming and politics is Wu wei 无 为—usually translated as ‘inaction’ or 'non-action,' meaning, more accurately, something like 'act naturally' or 'effortless action.' This is the key to merging with the Way of nature: 'doing nothing,' which does not mean complete inaction, but rather doing what is natural. 'Do nothing and everything will be done' (wu wei er wu bu wei 无 为而无不为) - that is everything will be achieved of its own accord. The favorite metaphor of Daoists is water, which though softest of all things, wears away hardest. If left to itself, the universe proceeds smoothly according to its own intrinsic harmonies. Man's efforts to change or improve nature-also by naming and classifying reality— 
only destroy these harmonies and produce chaos.

The Dao De Jing is ultimately a work of universal scope that comments on politics, statecraft, cosmology, aesthetics, and ethics. In the Daoist worldview, each particular element has to be defined both in relation to our personal experience and to the cosmos. Thus names are relative. The opening of the Dao De Jing emphasizes the relativism in the relation between name and things:

The Way (Dao) that can be spoken of is not the constant Way;

The name that can be named is not the constant name.

The nameless is the beginning of Heaven and Earth;

The named is the mother of all things.' (Lao Zi 1999: 79)

Visual imagery, in the most comprehensive sense of signs, allegories, metaphors, and the whole symbolic universe of references, plays a dominant role, both in the Confucian and Daoist corpuses. Imagery informs the texts, and texts inspire iconographic representations. Both the essential nature of the Chinese character (zi 字) and the power of the classical texts make it difficult to sustain any possibility, in the experience of a constituted reality, based on a clear analytical distinction between images and words. Dao De Jing's highly influential commentator Wang Bi (王饴 226-249 CE) explored the nexus between language and images, and poignantly argued for an inborn nature of the image in the language:

\footnotetext{
The Image is what brings out concept; language is what clarifies the Image. Nothing can equal Image in giving the fullness of concept; nothing can equal language in giving the fullness of Image. Language was born of the Image, thus we seek in language in order to observe the Image. Image was born of concept, thus we seek in Image in order to observe the concept. Concept is fully given in image; Image is overt in language. (Wang Bi 1996: 63-64)
}

Reflecting on Wang Bi’s insights into the Chinese apparatus of representation, one cannot refrain from comparing his recognition of the interconnected nature of language and images, with the intuition Roman poet Horatius (65-68 BCE) displayed, when, in the extraordinary 416 lines of his work known as Ars Poetica, ${ }^{1}$ he condensed Aristotle's lesson of poetry as a living organism. But Horatius also went one step further: he advocated 'equal right to dare to do' both to painters and poets (ut pictura poesis). Drawing on the etymological meaning of poíesis, from the Greek verb poiéin, which means to 'create,' 'to build,' Horatius insisted both on the importance of the process of building with words, accurately selecting and polishing them, and also on the inventio:

\footnotetext{
${ }^{1}$ Horatius's Ars Poetica was properly an epistle addressed to the Pisoni family.
} 
the choice of an original subject, or material for the creation. Therefore, his understanding of ars poetica referred specifically to the imaginative texts. Horatius argued that these texts deserved the same attention and the same careful interpretation that is traditionally offered to paintings. Horatius referred to the complete genre (which included not only poetry, but all forms of tragedy, dramatic action, satire, etc). However, Horatius's similitude between the two forms does not necessarily imply their equivalence. In his own words:

Poetry resembles painting. Some works will captivate you when you stand very close to them and others if you are at a greater distance. This one prefers a darker vantage point, that one wants to be seen in the light since it feels no terror before the penetrating judgment of the critic. This pleases only once, that will give pleasure even if we go back to it ten times over. (Horatius 2010: 400-6)

Horatius argued that the authors of imaginative texts had to responsibly know themselves, which implies knowing their limits, without falling into the trap of persecutory complexes, exhibitionisms, or poetic frenzies. Horatius saw imaginative texts as the outcome of a painstaking work, patience, study, and continuous correction, in one word: wisdom and not madness.

However, literary works and imaginative texts can also derive from madness (both in the creative and pathological sense), or describe individual or collective 'madness.' A case in hand is Lu Xun's word-image of 'man-eating-man,' that dominates his 1918 short story ‘Diary of a Madman’ (Kuangren riji 狂人日记) (Lu 1918: I, 422-33). Here Lu Xun used the allegory of cannibalism to critique traditional society: before 'being cured' the main character of the story wrote various entries in his diary (using vernacular instead of classical Chinese - which could be read in itself, at the time, as a sign of 'madness'), where he claimed to have seen the words 'Eat People!' between the lines of the classical Confucian texts. The delusional state of the alleged 'madman' led him to see all the people in his village as potential man-eaters. Lu Xun’s symbolic call to 'Save our children,' from what he saw as China's 'four-thousand years of cannibalism,' was to be contradicted, in reality, a few decades later. In the mid-1980s, well-known Chinese novelist Zheng Yi went to the Guangxi Zhuang Autonomous Region to conduct a thorough investigative report about the approximately 100,000 people who were massacred there during the Cultural Revolution. In his work, Zheng Yi documented the shocking facts about officially sanctioned cases of cannibalism, including interviews not only with family members of the victims, but also with some of 
the cannibals who described how the victims' bodies were carved up, shared among the killers, and eaten. In his work, accompanied by powerful photographs, Zheng Yi described the collective madness that dominated some of the most extraordinary 'feasts of human flesh,' like the one that occurred in Wuxuan County (武宣县) in June 1968. While Wuxuan locals tended to associate the outbreak of cannibalism at Wuxuan with the political meeting ‘to blow a twelve-degree typhoon of class struggle,' Zheng Yi concludes instead that these 'feasts' were due to the scarcity of food, even though he also highlights both the incredible cruelty (many victims were cannibalized while still alive), and the fact that the madness was not limited to Guanxi alone, since violence and ruthlessness occurred all over China at the time (Zheng 2002).

Imaginative texts can even become agents for violence. This was often the case during the Cultural Revolution. ${ }^{2}$ For example, the ‘ugly photograph’ of Liu Shaoqi’s wife, Wang Guangmei, wearing a body-clinging qipao dress (旗袍) during a banquet hosted by Indonesian President Sukarno in November 1963 during their State visit (Figures 1 and 2), ${ }^{3}$ sparked the violence against her in April 1967, when the Red Guards, perpetrating a grotesque historical nemesis, openly criticized her on public stage after

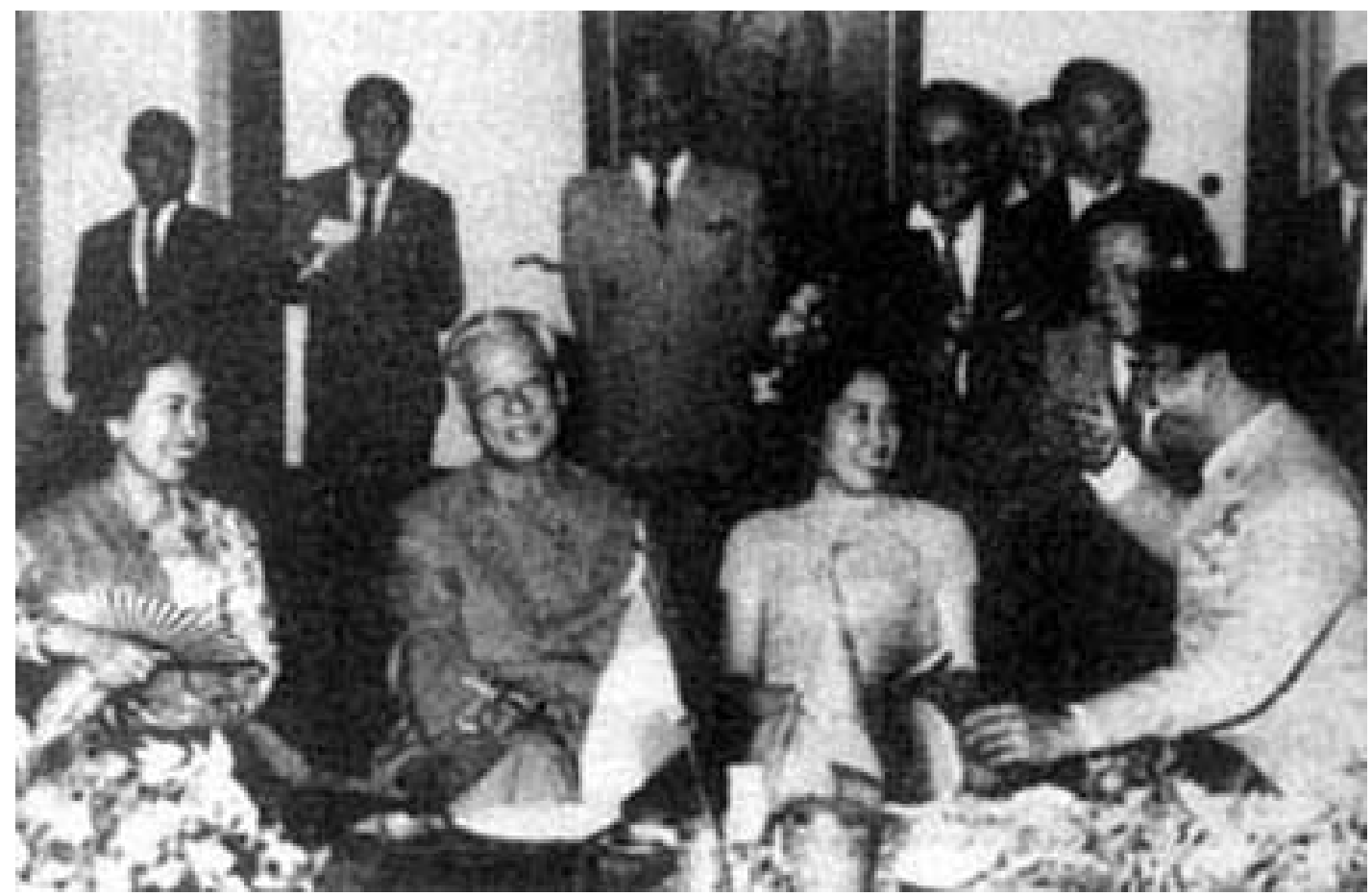

Figure 1: The official banquet hosted by President Sukarno during Liu Shaoqi's and Wang Guangmei’s state visit to Indonesia in November 1963.

\footnotetext{
${ }^{2}$ For images of depictions of violence in Cultural Revolution posters, see: http://news.qq.com/a/20120422/000881.htm\#p=1

${ }^{3}$ See: http://www.gdcct.gov.cn/politics/party/201201/t20120110_645050.html\#text
} 


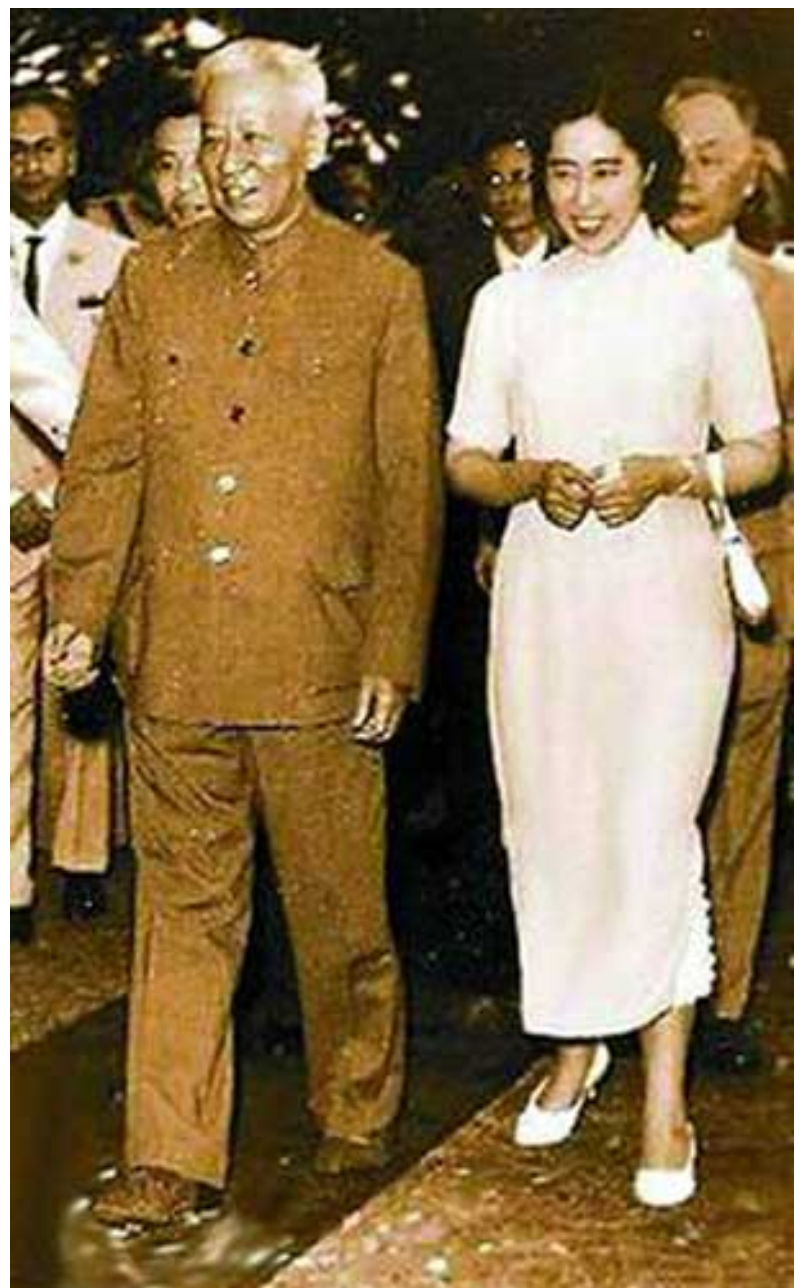

Figure 2: Liu Shaoqi’s state visit to Indonesia with Wang Guangmei.

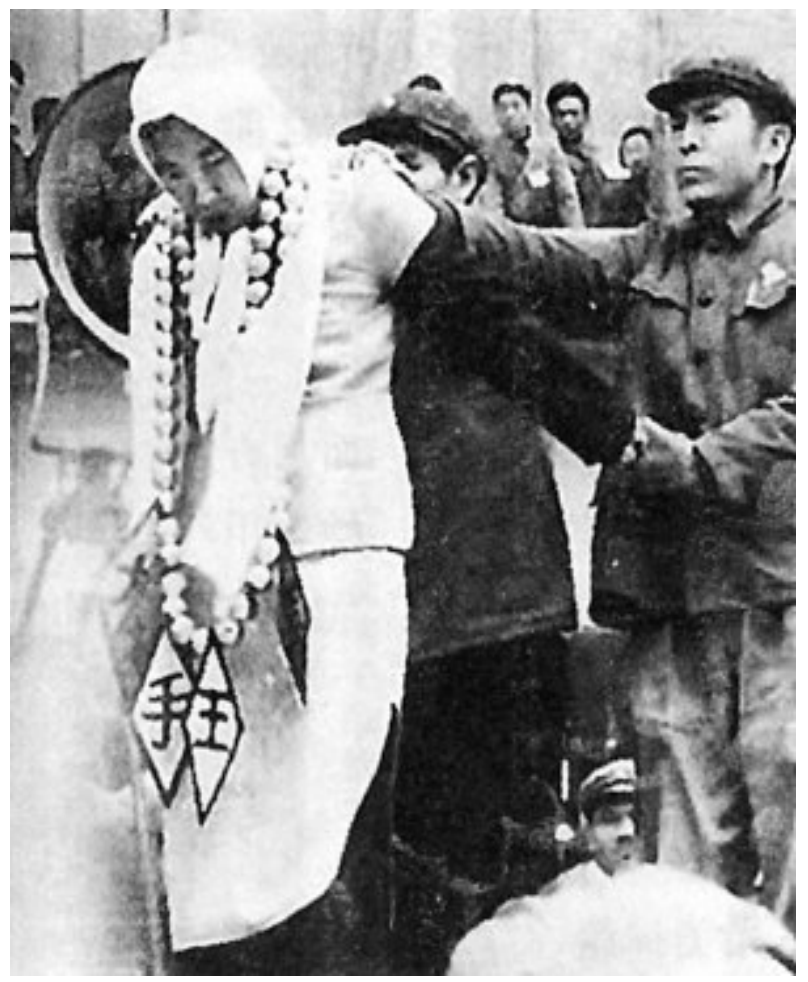

Figure 3: Wang Guangmei criticized by the Red Guards in April 1967. 
forcing her to put on the same dress, high heels and a flashy necklace made, this time, not with pearls but with ping pong balls (Figure 3). ${ }^{4}$

Language, images, word-images, or adopting Horatius's suggestion, imaginative texts, as the result of painstaking work, wisdom or madness (or a combination of the three elements), are the main focus of this Special Issue. The connecting thread between the five articles presented here is the authors' interest in the history, politics and aesthetics of word-images as a medium for the transmission of what could be defined as 'reality/realization,' following the intuition of esteemed Chinese artist Qiu Zhijie (邱志 杰). ${ }^{5}$

In his lecture entitled 'Total Art,' Qiu Zhijie pondered upon the Chinese compound word xianshi (现实). Qiu suggested translating xianshi into English as 'reality/realization,' respecting, in this fashion, the dual and interconnected semantic nature of the original Chinese compound word. He observed that xian was originally a verb, carrying the meaning of uncovering and, ultimately, demystifying what is behind. Qiu's following explanation immediately shifts from the universe of words per se to convey a sophisticated visual imagery: 现 xian meant 'To allow something that was not visible to become visible. Originally it lay dormant, now it is apparent. From dormancy to appearance: we might call "realization” the process wherein those things which might appear are turned into things which have appeared. In this way they are established. As this corresponds to art, it constitutes one type of art as a verb. One form is selected from amidst countless latent possibilities to effect this becoming real, this obtaining of appearance’ (Qiu Zhijie 2010).

This analytical framework could be applied to China, whose staged appearance of 'reality' to the world in the last three decades seemed to have been perceived as a sudden 'realization,' also due to the progressive prominence of Chinese imaginative texts and the work of avant-garde artists in particular. Paradoxically, the coming-out of China on the global stage, has followed a pattern that seemed to echo Timothy Mitchell's argument of the superiority complex of the Western paradigm of modernity,

\footnotetext{
${ }^{4}$ See: http://www.northnews.cn/2011/0601/361968.shtml. I would like to thank my colleague Fang Xiaoping both for discussing this theme with me and finding the relevant image.

${ }^{5}$ Artist, curator and writer Qiu Zhijie is Director of 'Total Art' Studio at the Chinese Academy of Art, Hangzhou. As a conceptual artist, Qiu’s practice includes painting, video, photography, installation, and theatre.
} 
that led the West to stage the 'World as Exhibition,' generating multiple distorting perceptions of the Other and projective assumptions of the West itself (Mitchell 1989: 217-36).

With regard to China today, paraphrasing Qiu Zhijie, one could say that something that was not visible (but that indeed existed) has become visible, but there is something in the interstices of power between the visible and the invisible that is worth studying and reflecting upon. In this sense, Qiu's thought-provoking reflections on 'reality/ realization' constitute a powerful incitement to discourse. It is an invitation to engage with the complex interplay between words and images, and explore their multiple possibilities of being and becoming situated in time and space, and ultimately to play a crucial role in the dialectics between power and knowledge.

Qiu Zhijie, today a famous artist and Chief Curator of the 2012 Shanghai Biennale, was one of the many Chinese artists who, in the mid-1980s, became fascinated with investigating and experimenting with the possibilities offered by the visual power embodied in Chinese characters. Other famous artists are Wu Shanzhuan (see Geremie Barmé's article in this special issue), Xu Bing 徐冰, and Gu Wenda 古文达 (Jiang 2008). The Maoist era and, according to these artists, the Cultural Revolution in particular, had privileged the function of the Chinese characters as bearers of a precise political message, since, as Xu Bing poignantly said, 'The Chinese language directly influences the methods of thinking and understanding of all Chinese people. To strike at the written word is to strike at the very essence of our culture. Any doctoring of the written word becomes in itself a transformation of the most inherent portion of a person's thinking' (Xu Bing 2001: 14).

The Cultural Revolution tactics of striking at words was strictly connected with the strategy of striking hard using words as instigators of extremely violent acts, and combining word-images to produce a sense of absolute totality. In the post-Cultural Revolution era, the awareness of the power of images and the treachery of characters, profoundly influenced another generation of 'characters workers' (wenyi gongzuozhe 文 艺工作者), who engaged with 'an aesthetic embrace of the principles of traditional writing' (Xu Bing 2001: 14) in unorthodox and witted ways, experimenting with character-play, and ultimately deconstructing the formerly unassailable absolute totality. Qiu Zhijie was one of those 'characters workers.' His most important early work was 
elaborated over three years (1992-1995), and is entitled 'Copying “Orchid Pavillon Preface” a Thousand Times’ (Shuxie yiqianbian Lantingxu 书写一千遍兰亭序) (Figure 4). It was inspired by the masterpiece Lantingjixu 兰亭集序, by Wang Xizhi 王羲之 (303-61 $\mathrm{CE}$ ), which is considered a classic of Chinese calligraphy. One would imagine that Qiu's title alluded to the calligrapher's practice of faithfully copying over and over the famous Preface, using, therefore, several sheets of paper. Copying calligraphic master works is part of a longstanding tradition for artists in China. However, what Qiu decided to do instead was to copy the characters a thousand times over the same sheet of rice paper. The final outcome was a sheet of paper saturated with black ink. The traditional act of 'copying' had led to the opposite of the expected climax of permanence and beauty: the erasure of the text. Art historian Wu Hung interpreted this asserting: ،“Copying Orchid Pavilion Preface a Thousand Times” can be seen as a postmodern deconstruction of traditional Chinese calligraphy, an art form linked to China's unique cultural heritage.' (Wu \& Wang 2010: 185).

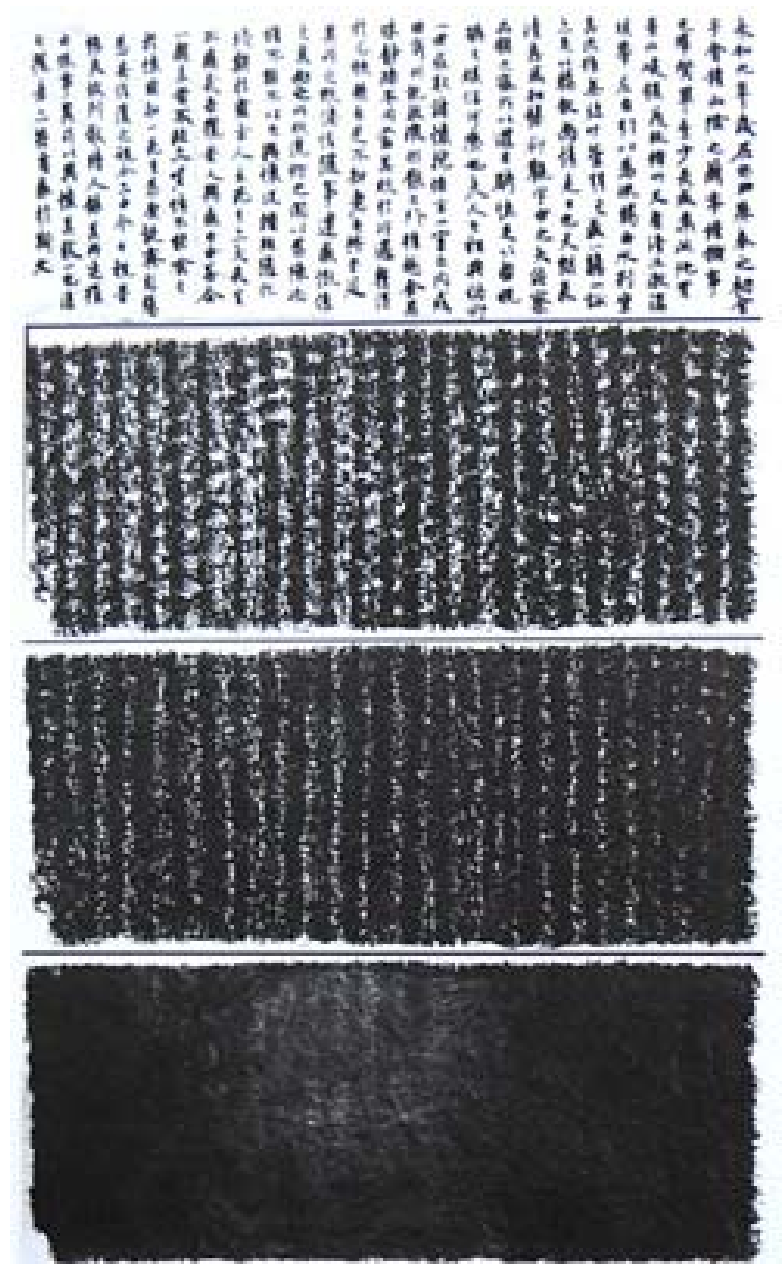

Figure 4: Qui Zhijie:

‘Copying “Orchid Pavillon Preface” a Thousand Times’ (Qiu Zhijie 2009-2010). 
This special issue derives from a multidisciplinary project, which draws on the individual expertise of the contributors, who are all China scholars respectively engaged in research across the disciplines of history, art history, human geography, and cultural studies. The content of these articles originated from an invitation to ponder upon the interrelation between 'words' and 'images' in Imperial, modern and contemporary China. The essays presented in this special issue offer in-depth 'realizations' on the interplay of word-images, and shed light on the processes of power that underlie their interaction and metamorphosis.

The essays presented here are the outcome of a careful re-elaboration of papers, which had originally been prepared for public presentation at the International Conference on 'Word and Image-East and West,' held in Sydney on 28-29 October 2011. ${ }^{6}$ In 1991 Mieke Bal defended the verbal and textual aspects of visual artifacts, arguing that a new cultural paradigm exists based on the assumption that 'the culture in which works of art and literature emerge and function does not impose a strict distinction between the verbal and the visual domain. In cultural life the two domains are constantly intertwined' (1991: 5). As the articles of this special issue will demonstrate, a strong case could be made to support the interconnectedness between verbal and visual domains also in the political sphere, both in the past and the present.

These papers reveal a few significant common threads. First, there is an interest of the contributors in posing critical questions about the relation between history and culture, language and politics, and the relevant ability to proffer their argument using both textual and iconographic sources adequately interpreted within an international cultural reference framework. Second, the authors undertake careful investigations of the historical memory and historical layers of writing and re-writing by means of a detailed perception of the interrelation between visual and textual evidence, offering also original critical interpretations.

Broadly speaking, this special issue contains papers that aim to critically engage with various aspects of Chinese culture, history, politics and aesthetics, going beyond the staged appearance of China's 'reality' to the world. The fundamental aim of the

\footnotetext{
${ }^{6}$ The Conference was organized by the University of Sydney and also supported by the China Research Centre, University of Technology Sydney. I would like to take this opportunity to thank the organizers, Francesco Borghesi and Giorgia Alù.
} 
contributors is their intention to offer well-informed, scholarly, and critical perspectives on the ways in which the 'imagined' and the 'real' become visible in the political and cultural realms.

The special issue opens with Duncan Campbell's article, 'Mortal Ancestors, Immortal Images: Zhang Dai’s Biographical Portraits.' Campbell delves into the last completed work of the important late-Ming historian and essayist Zhang Dai 張岱 (1597-?1684): Ming yuyue sanbuxiu mingxian tuzan 明於越三不朽名賢圖贊 (Portraits of the Eminent Worthies of Zhejiang during the Ming Dynasty whose Lives Embodied the Three Eternals). Zhang Dai's book included the biographies and portraits of 109 residents of his hometown Shaoxing (including Zhang's friends and family members), and it was organized according to the 'Three Eternals' of a life well and usefully lived: Virtue, Deed, and Word. Shaoxing was one of the epicentres of seventeenth-century China's élite cultural life. Campbell explores the text-image dialectic through an in-depth analysis of Zhang Dai's 'biographical portraits.' Therefore, the special issue opens with an essay that contributes to the scholarship which reflects the recent 'visual turn' in Chinese studies and the humanities more generally.

Duncan Campbell's work is followed by Claire Roberts's article on the artwork of scholar-artist Huang Binhong (黄宾虹 1865-1955). Today, Huang Binhong’s art collection, including hundreds of historic seals and ancient paintings, together with a large archive of his own paintings, calligraphy and personal papers, are core collections of the Zhejiang Provincial Museum in Hangzhou. Huang's classical education, with deep foundations in text-based historical learning, resulted in creative expression in the form of painting, calligraphy and seal carving. While based on cultural traditions of the past, these scholarly arts were directed at experiencing the present and imagining the future. Calligraphy and painting may be understood as the living embodiment of the artist who is vitally connected to the historical past, whereas the printed impression of words or images carved into stone conveys ideas associated with authenticity, longevity and artistic completion. When combined in a brush-and-ink painting there is an interesting tension between the spiritual and temporal; the ancient inscriptions and contemporary creativity, that Roberts explores in her essay thanks to her particular attention to the interconnection between the importance of place and learning in Huang's work. Through this case study, Roberts invites us also to reflect on ways that 
contemporary Chinese artists have drawn on the mutual interdependence of word and image to create compelling works of experimental art. This is the link between the first two essays and the following three of this special issue.

Geremie Barmé’s contribution, entitled 'History Writ Large: Big-character Posters, Red Logorrhoea and the Art of Words,' is part of a series of essays related to 'red revivalism' in contemporary China. Barmé's starting point is the 1986 artwork of the then Xiamenbased artist Wu Shanzhuan, called 'Red Humor,' which reworked references to bigcharacter posters (dazi bao 大字报) and other Mao-era forms of political discourse, recalling the Cultural Revolution. Barmé explains how Wu's installation offered a provocative microcosm of the overwhelming mood engendered by a logocentric movement to 'paint the nation red' with word-images during the years 1966-1967. This discussion of the hyper-real use of the dazi bao during China's Cultural Revolution era (c. 1964-1978) allows Barmé to probe into 'the legacies of the word made image' in modern China. The author analyzes the construction and deconstruction of the Chinese character (zi 字), by detecting a lineage for Wu's artwork in the bapo (八破 eight-fragments bricolage work of the late-Qing era). He then moves forward into the present-day to discuss the elaboration in the recent era of Chinese hypermodernity of 'demolition and forced relocation' (chaiqian 拆迁), an urban developmental model which shares similar characteristics of excess and abuse to the use of words and images. As Barmé argues, since the 1980s, Wu Shanzhuan has had many emulators and 'avant-garde successors,' since we have seen multiple examples of parodic deconstructions of the cultural authority of the Chinese character ( $z i$ 字) in recent decades.

The fourth article of the collection offers a significant example of the extremism in the use of characters and the related text-images. In his article, entitled 'Civilising the Citizens: Political Slogans and the Right to the City,' Maurizio Marinelli, who is also the editor of this special issue, concentrates on the artwork of Beijing-based artist Zhang Dali 张大力 called 'Slogan Series.' This article begins with an analysis of the logocentric mode which dominated the streets of Beijing in the lead up to the Olympic Games. The euphoria over the Olympics allowed the propaganda machinery to integrate all the key elements of the slogans used in the previous period, with the aim of promoting a 'civilized' behaviour in the citizens of the capital. Zhang Dali's artwork, 'The Slogan Series,' can be interpreted as an aesthetic response to that civic political campaign. The 
artist's critical assessment of the violence of the Olympics' hegemonic language, led him to appropriate the language of State propaganda to create uncanny text-images, with the aim of preventing collective amnesia, and advocating the right to speak a different language to inhabit the city. The incessant reproduction of slogans seems to have generated a collective anaesthesia, since ‘the citizens watch them but don't really see them' (Zhang 2009). This is the reason why Zhang Dali has decided to juxtapose people with slogans. The article investigates the social and emotional implications of a double juxtaposition: the slogans juxtaposed with the cityscape in the Government's 'new citizenship' campaign, and the slogans imposed and exposed on the people's faces in Zhang Dali’s work.

The fifth article, by Carolyn Cartier is entitled 'Image, Precariousness and the Logic of Cultural Production in Hong Kong.' The focus is on different modes of time-space in a selected place, Hong Kong, which is increasingly marginalized under the dominant master narrative of 'China’s rise.' Taking issue with Abbas’s famous definition of Hong Kong, on the eve of the 1997 handover, as a 'culture of disappearance'-which conveys the idea of any cultural expression made in Hong Kong as instantaneous and doomed to be short-lived-Cartier instead proposes using Jacques Rancière’s concept of the 'redistribution of the sensible.' By so doing, she demonstrates how multiple forms of artistic and cultural production can render visible different spatialities and temporalities. The article investigates the aesthetics of politics, examining the production of art in Hong Kong through community art exchanges, political graffiti, installation and alternative performance art, including the juxtaposition of two simultaneous events: the exhibit 'Memories of 的 King Kowloon' on the historic graffiti of Tsang Tsou-choi 曾灶财, with the projection of images of Ai Weiwei 艾未未 on to streets and walls across the city. Cartier shows how the ephemeral artworks also claim Hong Kong's historic times, past times of identity formation, pre-PRC Chinas and possible alternative futures, in juxtaposition with political tensions in the Special Administrative Region.

\section{Reference List}

Bal, M. 1991, Reading Rembrandt: Beyond the Word-Image Opposition. Amsterdam University Press, Amsterdam. Barmé, G. 1999, In the Red: On Contemporary Chinese Culture. Columbia University Press, New York. 
Cheng, M., 2009, ‘De/Visualizing Calligraphic Archeology: Qiu Zhijie’s Total Art,' The Drama Review, vol. 53, no. 2: 17-34.

Confucius 1960, The Analects, in The Chinese Classics, trans. J. Legge. Hong Kong University Press, Hong Kong. Reprinted [1893-1895]), vol. 1, 1861. Confucius’s Analects are also available online: http://nothingistic.org/library/confucius/analects [Accessed 7 July 2011].

Davis, G. (ed.) 2010, A Companion to Horace. Wiley-Blackwell, Chichester, \& Malden, MA.

Evans, H. \& Donald, S. H. 1999. Picturing Power in the People's Republic of China: Posters of the Cultural Revolution. Rowman \& Littlefield, Lanham.

Jiang, J. (ed.) 2008, The Revolution Continues. Random House, London.

Lao Zi. 1999. Trans. 'From the Daodejing,' by I. Bloom. In Sources of Chinese Tradition, (eds) W. T. De Bary, et al. vol. 1. Columbia University Press, New York: 79-80.

Lu Xun. 1918, 'Kuangren riji’ (Diary of a Madman), in Lu Xun Quanji, I, 422-33; Selected Works, I: 821.

Makeham, J. 1994, Name and Actuality in Early Chinese Thought. State University of New York, Albany.

Mitchell, T. 1989, 'The World as Exhibition,' Comparative Studies in Society and History, vol. 31, no. 2: 217-36.

Qiu Zhijie. 2009-2010, 'Copying a Thousand Times the Orchid Pavilion Preface (1990-1995).' Online, available:

http://www.huancuitang.org/en/style_and_attitude/grace_and_resilience/calligraphy_of_consolatio

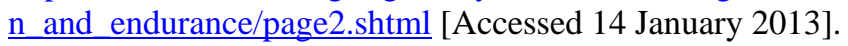
2010, ‘Total Art,’ trans. J. D. Lee \& R. Karl. Online, available: http://www.qiuzhijie.com/ecritiquelunwen/016.htm [Accessed 15 September 2012].

Schoenhals, M. 1992, Doing Things with Words in Chinese Politics: Five Studies. University of California at Berkeley, Berkeley.

Xu Bing. 2001, 'The Living Word,' in The Art of Xu Bing Words without Meaning, Meaning without Words, ed. B. Erickson. University of Washington Press, Seattle and London.

Wang Bi, 1996, 'Elucidation of the Images,' Classic of Changes. In Owen, S. (ed. \& trans.), An Anthology of Chinese Literature: Beginnings to 1911, W.W. Norton \& Co., New York: 63-64.

Wittgenstein, L. 1961, Tractatus Logico-Philosophicus, (trans.) D. Pears \& B. McGuinness. Routledge, London: 5-6.

Wu, H. \& Wang, P. 2010, Contemporary Chinese Art: Primary Documents. Museum of Modern Art, New York.

Zheng Yi. 2002, Scarlet Memorial: Tales of Cannibalism in Modern China, ed. and trans. T. P. Sym. Westview Press, Boulder. (For the extended original version see: Zheng Yi, Hongse Jinianbei [The Red Memorial Plinth]. Huashi wenhua gongsi, Taipei).

\section{Chinese online sources}

文革期间的 “暴力” 宣传画 (Propaganda Posters on “Violence’ from the Cultural Revolution Era). Online, available http://news.qq.com/a/20120422/000881.htm\#p=1 [Accessed 14 January 2013].

王光美享誉海外被江青记恨 文革中惨遭批斗 (Wang Guangmei was Envied by Jiang Qing for Her International Fame, and She Was Harshly Criticized During the Cultural Revolution), 2012 (10 January). Online, available:

http://www.gdcct.gov.cn/politics/party/201201/t20120110_645050.html\#text [Accessed 14 January 2013]. Original article appears in: 叶永烈 (Ye Yonglie): 《出没风波里》 (Chumo Fengboli) [Inside and Outside Turmoil], 北京: 十月文艺出版社。October Literature and Art Publishing House, Beijing: 2007 年。

什么原因使江青欲在文革中整死王光美 (The Reason Why Jiang Qing Criticized and Persecuted Wang Guangmei to Death During the Cultural Revolution), 2011 (1 June). Online, available: http://www.northnews.cn/2011/0601/361968.shtml [Accessed 14 January 2013]. Original article appears in: 叶永烈 (Ye Yonglie): 《出没风波里》 (Chumo Fengboli) [Inside and Outside Turmoil], 北京：十月文艺出版社。October Literature and Art Publishing House, Beijing: 2007 年。 